\title{
Entrepreneurs Can Benefit Society
}

\section{Daniel Forbes (University of Minnesota)}

Eden Blair (Bradley University)

KEYWORDS: Entrepreneurship, Innovation.

Entrepreneurs play a huge role in society by bringing underappreciated products to market -- products that can help people but that big companies are too busy or disinterested to develop. In the process of developing these hidden gems, entrepreneurs build great companies, create jobs and carve out careers that are professionally and personally rewarding. Daniel Forbes of the University of Minnesota and Eden Blair of Bradley University discuss how entrepreneurs can benefit society and do things their own way. 